\title{
Latitudinal- and local-scale variations in a rocky intertidal interaction web
}

\author{
E. Maggi ${ }^{1, *}$, M. Milazzo ${ }^{2}$, M. Graziano ${ }^{3}$, R. Chemello ${ }^{2}$, L. Benedetti-Cecchi ${ }^{1}$ \\ ${ }^{1}$ Dipartimento di Biologia, Università di Pisa, CoNISMa, Via Derna 1, 56126 Pisa, Italy \\ ${ }^{2}$ DISTeM, Università di Palermo, CoNISMa, Via Archirafi 22, 90123 Palermo, Italy \\ ${ }^{3}$ European Commission, Joint Research Centre, Via Enrico Fermi 2749, 21027 Ispra, Italy
}

\begin{abstract}
Natural assemblages are structured by a complex combination of positive and negative interactions, and the relative importance of each interaction can vary across spatial scales. By using a simple interaction web (barnacles-grazers-microphytobenthos) in a rocky intertidal system, we tested the hypothesis that the relative strength of positive and negative interactions would vary as a function of different environmental stress between 2 latitudinal levels and local environmental conditions. We manipulated the cover of barnacles and the presence of limpets at 2 sites in northern and southern Italy and non-destructively examined the response of microphytobenthos (MPB) (photosynthetic biomass, $F_{0}$, and maximum efficiency, $F_{\mathrm{v}} / F_{\mathrm{m}}$ ) and of its small-sized grazers (littorinids). At northern sites, a density-dependent facilitative effect of barnacles on $F_{0}$ was detected. The effect was likely due to the addition of favourable secondary habitat (i.e. barnacle shells) and amelioration of abiotic conditions to nearby rock. At southern sites, a positive effect of increasing barnacle cover was observed on littorinid density. The subsequent indirect trophic effect on $F_{0}$, in addition to local nutrient input from anthropogenic activities, likely masked the positive effects of increasing cover of barnacles on $F_{0}$ at this latitude. No factors influenced $F_{\mathrm{v}} / F_{\mathrm{m}}$, suggesting a lack of changes in the relative abundance of MPB species. There was no effect of excluding herbivores at either latitude. Results suggest that species interactions supported by foundation species might be undermined by the concomitant action of temperature-related changes and local anthropogenic stressors, whose interactive effects are likely to become more severe with global climate change.
\end{abstract}

KEY WORDS: Facilitation $\cdot$ Density dependence $\cdot$ Indirect effects $\cdot$ Environmental stress $\cdot$ Local stressors $\cdot$ Microphytobenthos $\cdot$ Barnacles $\cdot$ Grazing $\cdot$ Interaction web

\section{INTRODUCTION}

The idea that patterns and processes vary across biogeographic spatial scales has a long history in ecology (Fischer 1960). The strength and nature of biological interactions (such as competition, herbivory and predation) vary as a function of many factors (e.g. abiotic conditions, population densities and the genetic make-up of species; Thompson \& Cunningham 2002, Menge et al. 2003). These moderating processes of species interactions are themselves vari- able across large spatial scales, such as latitudinal gradients, and at more local scales (Crowe et al. 2013, Doxford et al. 2013). Despite increasing interest in understanding whether species interactions are general or context dependent (Chamberlain et al. 2014), experimental studies that enable comparisons over a broad range of spatial scales remain relatively rare (e.g. Leonard 2000, Menge et al. 2002, Pennings \& Silliman 2005).

Early theories on the causes of variability in the intensity and nature of biotic interactions were cen- 
tred on the role of abiotic factors in regulating predation or competition (e.g. the consumer stress model; Menge \& Olson 1990). Later, the key role of positive interactions between species was recognized and the concept of facilitation included within key ecological models (Bruno \& Bertness 2001). One of the most influential of these theories predicts that when stressful conditions become too extreme, competitive interactions are replaced by positive ones, for example through the amelioration of the abiotic environment (the stress gradient hypothesis, Bertness \& Callaway 1994).

Although stressful environmental conditions (e.g. environmental harshness, thermal stress) may covary with latitudinal gradients, studies investigating changes in the strength of positive interactions across latitudes are scarce (but see Leonard 2000, Bertness \& Ewanchuk 2002, Doxford et al. 2013). Similarly, while facilitation by foundation species is widely recognized (Dayton 1972), little is known of how trait variation within the benefactor species or population can modify the strength of facilitative effects by changing the amount of habitable space or amelioration of environmental stress (Leonard \& Luther 1995). For example, recent experimental studies highlighted how changes in the abundance of either plant or animal species were key in determining the nature of their effects (i.e. positive vs. negative) on intertidal and subtidal organisms (e.g. Irving \& Bertness 2009, Maggi et al. 2009). The occurrence of different types of indirect effects further complicates the scenario (Menge 1995). Apparent competition (where the reduction of a species results from increases in a second species, which enhances predation by a common consumer; Holt 1977) was probably the first of a multitude of indirect effects postulated by theorists. Facilitation itself may originate indirect species interactions, such as when the facilitator reduces the effect of a consumer on a third species (an interaction modification sensu Wootton 1993) (Bruno \& Bertness 2001). When indirect effects are present, predictions of the outcome of a particular interaction may be difficult, unless all interacting species are manipulated (Menge 1995). For example, indirect effects can cancel apparently straightforward positive effects of a benefactor on a species by driving responses in the opposite direction (e.g. if the benefactor also facilitates a consumer) (Menge \& Branch 2001). All of these different aspects of species interactions should be taken into account to fully understand assemblage dynamics.

Rocky intertidal habitats offer ideal systems to investigate variations in positive direct and indirect biotic interactions at different spatial scales. Intertidal rocky shores are characterized by harsh physical conditions (Benedetti-Cecchi \& Trussell 2014), so that positive interactions mainly consist of the amelioration of abiotic conditions by sessile species, such as canopy-forming algae, mussels and barnacles (Bulleri 2009 and references therein). However, there are several examples of non-trophic modifications to the activity of herbivores or predators, which result in indirect positive effects on prey (Creese 1982, Dungan 1986). In addition, major abiotic stressors acting in these habitats (such as thermal and desiccation stress) may also vary at broad spatial scales (e.g. latitudinal), making large-scale experimentation on variation in biotic interactions important to understanding responses of assemblages to changes in climatic conditions (Leonard 2000).

Barnacles are common sessile organisms in rocky intertidal habitats along the world's temperate coasts (Stephenson \& Stephenson 1949). At high densities, they can modify temperature or humidity levels (Kawai \& Tokeshi 2004) as well as reduce the movement of dominant gastropods (Creese 1982, Freidenburg et al. 2007), hence potentially facilitating algae inhabiting the rocky intertidal (Benedetti-Cecchi 2000). Many studies have investigated pairwise interactions within assemblages of barnacles, limpets and algae on different temperate and tropical shores (e.g. Underwood 1979, Hawkins \& Hartnoll 1983, Williams et al. 2000). However, less attention has been paid to understanding indirect interactions within this system (but see Dungan 1986, BenedettiCecchi 2000).

Using the comparative experimental approach (e.g. Menge et al. 2002), we investigated variations in the intensity and direction of biotic interactions at local (tens of kilometres) and latitudinal (thousands of kilometres) scales in the western Mediterranean using a simple interaction web (Paine 1980) that includes both trophic (grazing) and non-trophic (driven by changes in cover of a foundation species, namely barnacles) interactions. The interaction web comprised sessile barnacles Chthamalus spp., limpets $\mathrm{Pa}$ tella spp., littorinids and microphytobenthos (MPB) that typically occur on Mediterranean rocky shores. MPB play a key ecological role in shallow marine and intertidal areas, contributing to primary productivity and providing food to many gastropod grazers (Thompson et al. 2000). Grazing, thermal stress, light and nutrient availability can significantly affect the biomass and photosynthetic performance of MPB (Thompson et al. 2004). We hypothesized that barnacles can provide refuge to MPB from limpet grazing, 
as has been observed for macroalgae (BenedettiCecchi 2000). Due to the large size of these herbivores relative to the size of barnacles, we expected limpets to be limited in their grazing activity both between and over barnacle shells (Creese 1982 and references therein). In addition, we hypothesized a direct positive effect of barnacles on MPB biomass and photosynthetic activity due to the provision of a biogenic refuge from higher thermal and desiccation stress, as has been observed for littorinids and mussels (Kawai \& Tokeshi 2004, Cartwright \& Williams 2012); this effect was expected to be larger at southern than at northern sites. We also expected barnacle shells to represent a favourable habitat for the grazing activity of littorinids due to the small size of these grazers relative to that of barnacles (Creese 1982, Díaz et al. 2012).

To test these hypotheses, we experimentally manipulated barnacle cover and the presence/absence of limpets in a factorial design at northern and southern sites. We quantified effects on littorinids and on MPB photosynthetic biomass and activity, either on the rock surface or on barnacle shells, by means of in situ fluorescence. We expected (1) larger biomass and maximum photosynthetic efficiency of MPB and density of littorinids at larger barnacle covers, particularly at southern sites, where environmental conditions were harsher and (2) smaller MPB biomass in the presence of than in the absence of limpets, this effect being smaller at larger covers of barnacles due to reduced efficiency of limpet grazing on barnacle shells.

\section{MATERIALS AND METHODS}

\section{Study sites}

The study was done between December 2007 and May 2008. The experiment was repeated at 2 sites about $70 \mathrm{~km}$ apart along the northwestern coast of Italy ('North', Tuscany region; Site 1: $44^{\circ} 02^{\prime} \mathrm{N}, 9^{\circ} 59^{\prime} \mathrm{E}$; Site 2: $43^{\circ} 28^{\prime} \mathrm{N}, 10^{\circ} 20^{\prime} \mathrm{E}$ ) and at 2 sites about $10 \mathrm{~km}$ apart on the southwestern coast ('South', Sicily region; Site 1: $38^{\circ} 11^{\prime} \mathrm{N}, 13^{\circ} 14^{\prime} \mathrm{E}$; Site 2 : $38^{\circ} 10^{\prime} \mathrm{N}$, $\left.13^{\circ} 13^{\prime} \mathrm{E}\right)$. The 2 levels of latitude spanned about $1000 \mathrm{~km}$. In Tuscany, the substratum was sandstone at Site 1 and schist at Site 2, while in Sicily, it was limestone at both sites. Climatic conditions differ between the northern and southern sites. During the study, both air temperature (AT) and sea surface temperature (SST) were higher at the southern sites (AT: South: $15.5 \pm 0.3^{\circ} \mathrm{C}$, North: $7.2 \pm 0.3^{\circ} \mathrm{C}$, mean daily data, source: www.ilmeteo.it; SST: South: $15.8^{\circ} \mathrm{C}$, North: $13.7^{\circ} \mathrm{C}$, mean weekly data, source: NOAA AVHRR_Pathfinder_V5, http://podaac.jpl).

Assemblages occurring between 0 and $0.5 \mathrm{~m}$ above mean low water level on these coasts were characterized by patches of encrusting barnacles (mostly Chthamalus stellatus [Poli], but C. montagui [Southward] was also present at the northern sites), separated by apparently bare rock colonized by MPB (generally composed of cyanobacteria, diatoms, macroalgal spores and germlings; Della Santina \& Chelazzi 1991, Jackson et al. 2010). MPB also colonize adult barnacle shells (Thompson et al. 1996). Encrusting or erect macroalgal species were sometimes present but in small covers (Benedetti-Cecchi 2000) and were therefore not considered. Colonies of encrusting cyanobacteria (mainly Rivularia atra [Roth] and $R$. mesenterica [Thuret]) were also present. The most common herbivores were the limpets Patella ulyssiponensis (Gmelin), P. caerulea (Linnaeus) and $P$. rustica (Linnè) (the last being present only at the northern sites; see Table S1 in the Supplement at www.int-res.com/articles/suppl/m534p039 _supp.pdf for densities of limpets at the study sites); littorinids (Melaraphe neritoides [Linnè] and, along the southern coasts, Echinolittorina punctata [Gmelin]) and chitons were also present.

\section{Experimental design}

Before the experiment, at each site, we estimated the mean percentage cover of barnacles in 20 plots randomly chosen from areas of rock where barnacles were present. Cover was estimated with a plastic frame, $15 \times 15 \mathrm{~cm}$, divided into 16 sub-quadrats. A score from 0 (absence) to 4 (full cover) was given in each sub-quadrat, and a final estimate was obtained by summing individual scores over the 16 subquadrats (Dethier et al. 1993), for a maximum of 64 . Values were then expressed as percentages.

For the set-up of the experiment, at each site, 27 plots $(15 \times 15 \mathrm{~cm})$ were randomly selected along a $100 \mathrm{~m}$ stretch of coast from areas characterized by a percent cover of barnacles approximately matching the mean value observed at that site (North: Site 1 $[\mathrm{SN} 1]=59 \%$; Site $2[\mathrm{SN} 2]=74 \%$; South: Site 1 [SS1] and Site $2[\mathrm{SS} 2]=47 \%$ ). Plots were then randomly and evenly assigned to 1 of 3 levels of cover of barnacles (factor Barnacles): 100, 50 or $0 \%$ (complete removal) of the mean cover at each site. Barnacles were removed using a paint scraper, and care was taken not to damage the surrounding rock and asso- 
ciated MPB. To remove $50 \%$ of mean cover of barnacles at each site, we randomly selected several areas of 4 to $8 \%$ of cover within the quadrat (representing altogether $50 \%$ of cover of barnacles) and removed all barnacles within them. Relative differences among levels of the Barnacles treatment were maintained until the end of the experiments (Table S1). Three of the 9 plots within each level of Barnacles were then assigned to each of 3 levels of presence/absence of limpets (factor Herbivore): control, exclusion and procedural controls (PC). Except for the exclusion treatment (where limpets were permanently removed), densities of limpets were not manipulated and might consequently have differed between sites and times (see Table S1). Control plots were marked at their corners with epoxy putty (Subcoat S, Veneziani), while full and partial fences $(15 \times 15 \times 4 \mathrm{~cm})$ were used to create exclusion and PC treatments, respectively. Fences were made of metal mesh covered with plastic (12 $\mathrm{mm}$ mesh size) and reinforced with a galvanized mesh $(6 \mathrm{~mm})$ to resist wave impact. Fences were anchored to the substratum with stainless-steel screws inserted into plugs in the rock. The mesh size $(12 \mathrm{~mm})$ allowed water flow and entrance of smaller grazers (e.g. littorinids), while excluding limpets (Tables S1 \& S2). For logistical constraints (including weather conditions), experiments were done during different periods at the 4 sites (SN1: 17 December to 26 February 2007, SN2: 18 December to 25 February 2007; SS1: 14 February to 22 May 2008, SS2: 3 March to 22 May 2008).

\section{Sampling and analysis of data}

Plots were non-destructively sampled twice at each site (after about 40 and $70 \mathrm{~d}$ in the North; after about 60 and $95 \mathrm{~d}$ in the South). At each time, in vivo fluorescence of MPB was sampled through a portable underwater pulse-amplitude modulated (PAM) fluorometer (Diving-PAM, Walz). The probe was kept at $4 \mathrm{~mm}$ above the substratum and measured an area of approximately $24 \mathrm{~mm}^{2}$ (Area ${ }_{\mathrm{PAM}}$ ). Minimum fluorescence $\left(F_{0}\right)$ and the effective quantum yield of Photosystem II $\left(F_{\mathrm{v}} / F_{\mathrm{m}}\right)$ after dark adaptation were measured and used as a proxy of photosynthetic biomass and maximum photosynthetic efficiency of MPB, respectively (Serodio et al. 1997). Regression between $F_{0}$ and chl a concentration from laboratory analyses showed that minimum fluorescence can be used as a proxy for MPB biomass on rocky intertidal shores (chl a conc. $=0.004$ $\left.\times F_{0}+0.19, \mathrm{R}^{2}=0.70, \mathrm{p}<0.0001, \mathrm{n}=50\right)$. This tech- nique has been widely used to take non-destructive, relatively fast in situ measurements in different habitats; by taking measurements of $F_{0}$ and $F_{\mathrm{m}}$ at the same time, estimates of photosynthetic biomass and maximum efficiency refer to the same MPB samples.

At each sampling time, in each plot, 3 replicate measurements of $F_{0}$ and $F_{\mathrm{v}} / F_{\mathrm{m}}$ were randomly obtained from the rock surface and from barnacle shells (when present). Microtopography of the rock surface was usually less complex in comparison to the 3-dimensional structure created by barnacle shells; this could have caused values of $F_{0}$ sampled over barnacles to slightly underestimate MPB biomass in comparison to those sampled on the rock surface. Areas close to the edges of the fence (within $\sim 1 \mathrm{~cm}$ ) were not sampled, to prevent possible border effects. Since plots could be wet or dry depending on the presence of wave splash, they were wetted with seawater 5 min before sampling to obtain comparable values (as later confirmed by Maggi et al. 2013). Because the basal fluorescence of the substrata differed either among rock types (i.e. sandstone, schist and limestone) or between types of substrata (i.e. rock vs. barnacle shells), fluorescence values were standardized using measurements made on samples of rock or barnacle shells treated with sodium hypochlorite to remove any organisms.

The average of the 3 replicate measurements on either the rock surface $\left(F_{0_{\mathrm{ROCK}}} F_{\mathrm{v}} / F_{\mathrm{m}_{\mathrm{ROCK}}}\right)$ or barnacle shells $\left(F_{0_{\text {BARN }}}, F_{\mathrm{v}} / F_{\mathrm{m}_{\text {BARN }}}\right)$ was then calculated for each plot at each sampling time. Mean values of $F_{0}$ were then combined to estimate the total amount of MPB photosynthetic biomass present in each plot at each time $\left(F_{0_{\mathrm{TOT}}}\right)$ :

$$
\left.\left.\begin{array}{rl}
F_{0_{\mathrm{TOT}}}= & \left\{F_{0_{\mathrm{ROCK}}} \times\left[\left(\%_{\mathrm{ROCK}} \times \text { Area }_{\mathrm{PLOT}}\right) / \text { Area }_{\mathrm{PAM}}\right]\right\}+ \\
& \left\{F_{0_{\mathrm{BARN}}} \times\left[\left(\%_{\mathrm{BARN}} \times \text { Area }_{\mathrm{PLOT}}\right) /\right. \text { Area }\right. \\
\text { PAM }
\end{array}\right]\right\}
$$

where $\%_{\text {ROCK }}$ and $\%_{\text {BARN }}$ are the percentage cover of either rock surface or barnacle shells, respectively, at each sampling time in each plot, and Area PLOT $=$ $150 \times 150 \mathrm{~mm}$. Mean values of $F_{\mathrm{v}} / F_{\mathrm{m}}$ were combined to estimate the mean maximum photosynthetic efficiency of MPB in each plot at each time $\left(F_{\mathrm{v}} / F_{\mathrm{m}_{\mathrm{MEAN}}}\right)$ :

$F_{\mathrm{v}} / F_{\text {mMEAN }}=$

$\left[\left(F_{\mathrm{v}} / F_{\text {mROCK }} \times \%_{\text {ROCK }}\right)+\left(F_{\mathrm{v}} / F_{\text {mBARN }} \times \%_{\text {BARN }}\right)\right] / 2$

Macroscopic colonies of cyanobacteria and, when present, macroalgae were sampled using the same procedure described for barnacles, whereas littorinids were counted inside plots.

All data were analyzed by univariate analysis of variance (ANOVA) using the GAD package in $R$ 
v2.15.3 (R Development Core Team 2013). Due to different starting dates between northern and southern sites, analyses were run separately for each latitude and sampling time (Time 1 and Time 2). Each analysis consisted of 3 crossed factors: Site (random, 2 levels: S1 and S2), Barnacle (fixed, 3 levels: 100, 50 or $0 \%$; only 100 and $50 \%$ levels for data on barnacle shells) and Herbivore (fixed, 3 levels: control, exclusion and PC). Heterogeneity of variances was tested by Cochran's test.

\section{RESULTS}

\section{MPB biomass and photosynthetic activity}

At northern sites, total MPB biomass $\left(F_{0_{\mathrm{TOT}}}\right)$ was smaller at smaller barnacle covers (Time 1, Site $\times$ Barnacle interaction: $F_{2,36}=4.33, \mathrm{p}<$ 0.05, Student-Newman-Keuls [SNK] results: Site 1: $100>50>0 \%$, Site 2: $100>50 \%=0 \%$; Time 2, Barnacles main effect: $F_{2,2}=82.26, \mathrm{p}<0.05$, SNK results: $100>50>0 \%$ ) (Table S3 in the Supplement, Fig. 1A,B). Similar results were obtained when analyzing data of MPB biomass per unit area of rock surface $\left(F_{0_{\mathrm{ROCK}}}\right)$, showing a positive effect of the highest barnacle cover (Time 1, Site $\times$ Barnacle interaction: $F_{2,36}=4.23, \mathrm{p}<0.05$, SNK results: Site 1: $100>$ 0, 50\% not ranking, Site 2: $100>0 \%=50 \%$; Time 2, Barnacles main effect: $F_{2,42}=9.33, \mathrm{p}<0.001$, SNK results: $100>0 \%=50 \%$ ) (Table $\mathrm{S} 4)$. In contrast, barnacle cover had no effect on estimates of MPB biomass per unit area over barnacle shells $\left(F_{0_{\text {BARN }}}\right)$ (data not shown). Total MPB biomass values differed between southern sites at Time 1 (Site: $F_{1,36}=4.81$, $\mathrm{p}<0.05$ ) but not at Time 2 (Table S3). Total MPB biomass values decreased from Time 1 to Time 2 at each latitude.

In contrast to our hypothesis, the mean values of maximum photosynthetic efficiency of MPB $\left(F_{\mathrm{v}} / F_{\mathrm{m}_{\mathrm{MEAN}}}\right)$ were not smaller at smaller barnacle covers at southern sites but differed between northern sites at Times 1 and 2 (Time 1: $F_{1,36}=4.17, \mathrm{p}<0.05$; Time 2: $\left.F_{1,36}=5.81, \mathrm{p}<0.05\right)$ and between southern sites at Time 1 (Time 1: $F_{1,36}=18.97, \mathrm{p}<0.0001$ ) (Table S5).
Time 1

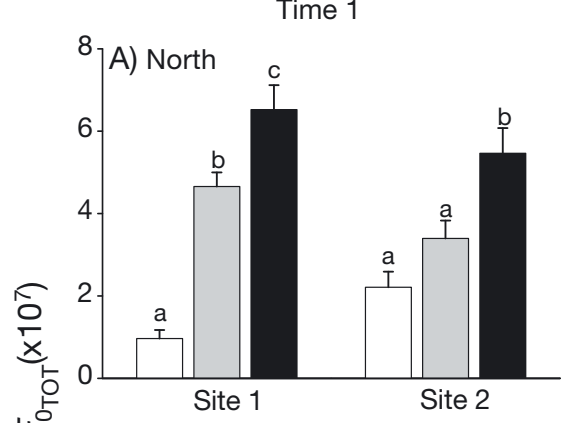

Fig. 1. Mean values (+1 SE) of total amount of microphytobenthos photosynthetic biomass (MPB $\left.F_{0_{\mathrm{TOT}}}\right)$ at $(\mathrm{A}, \mathrm{B})$ northern and $(\mathrm{C}, \mathrm{D})$ southern sites under Time 1 ( $A, C), n=9$. At Time $2(B, D)$, data are averaged across sites (n $=18)$ Different letters indicate significantly different treatments (Student-NewmanKeuls test). Note differences in scale between northern $(A, B)$ and southern $(\mathrm{C}, \mathrm{D})$ sites

\section{Macroalgal and cyanobacteria cover and littorinid density}

Erect algae were almost absent at northern sites at each time. In contrast, they unexpectedly attained large percentage covers in the South, especially at SS2 (Time 1: $F_{1,36}=23.19$, p $<0.0001$; Time 2: $F_{1,36}=15.32, \mathrm{p}<0.001$ ) (Table S6). Encrusting cyanobacteria Rivularia spp. were present only at Time 2 and were positively affected by barnacles only at one of the northern sites (North: $F_{2,40}=6.28$, $\mathrm{p}<0.01$; SNK: SN2: $100>50 \%=0 \%$ ) (Table S7, Fig. 2). Littorinids were affected by different factors at the 2 latitudes. In particular, at SN2, littorinids were significantly affected by the factor Herbivore at Time 1 (North: $F_{2,40}=3.68, \mathrm{p}<0.05$ ); post hoc comparisons indicated that there were significantly more animals inside exclusion than PC plots, with control plots ranking between them. In contrast, at SS2, the density of littorinids was significantly smaller in the absence of barnacles than in their presence (i.e. $100 \%=50>0 \%$ ) (Time 1: $F_{2,36}=$ 4.19, p < 0.05; Time 2: $F_{2,36}=6.27, \mathrm{p}<0.01$ ) (Table S8, Fig. 3). 


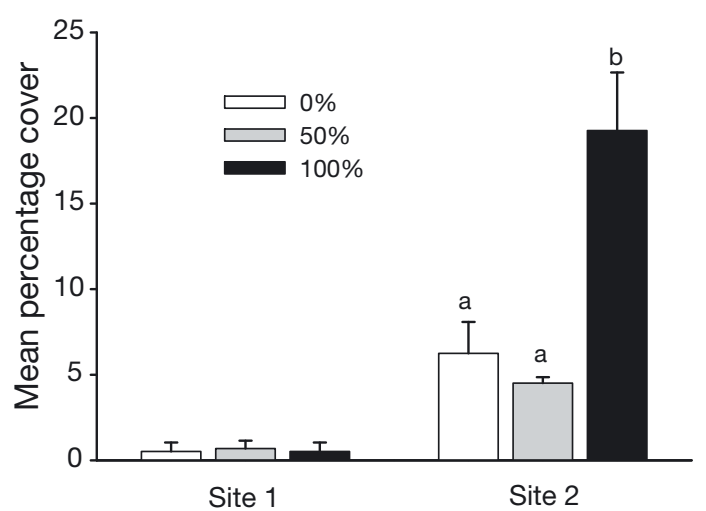

Fig. 2. Mean percentage cover $(+1 \mathrm{SE})$ of encrusting cyanobacteria at northern sites at Time 2 under 100, 50 or $0 \%$ (complete removal) of mean cover of barnacles at each site $(\mathrm{n}=9)$. Different letters indicate significantly different treatments (Student-Newman-Keuls test)

\section{DISCUSSION}

This study documented a density-dependent facilitative effect of barnacles on MPB biomass on Mediterranean intertidal rocky coasts but not on maximum photosynthetic efficiency. Unexpectedly, this effect was evident only at northern sites. No effect of excluding limpets on MPB biomass or maximum efficiency was detected at either latitude. At southern sites, a positive effect of increasing barnacle cover on density of littorinids was apparent.

During winter, northern Mediterranean rocky shores experience mild to cold air temperatures, so that thermal conditions can be considered benign for intertidal organisms (Benedetti-Cecchi et al. 2006). However, due to narrow tidal excursions, high barometric pressure may expose intertidal organisms to aerial conditions for long periods, increasing desiccation stress and depressing algal biomass (BenedettiCecchi et al. 2006). Under these conditions, large covers of barnacles can create a biogenic microhabitat, where cool interstitial air temperature and high humidity can reduce desiccation (Kawai \& Tokeshi 2004). The same mechanism of facilitation might explain the large cover attained by encrusting cyanobacteria Rivularia spp. in plots where barnacles were abundant at one northern site.

Interestingly, estimates of MPB biomass per unit area $\left(F_{0_{\mathrm{ROCK}}}\right.$ and $F_{0_{\mathrm{BARN}}}$ measured on $\left.24 \mathrm{~mm}^{2}\right)$ suggested that barnacles could affect primary producers in 2 ways. As shown on other European rocky shores (Thompson et al. 1996), barnacle shells directly provided a favourable habitat, with greater MPB biomass compared to rock surfaces (mean $\pm \mathrm{SE}$ at north-

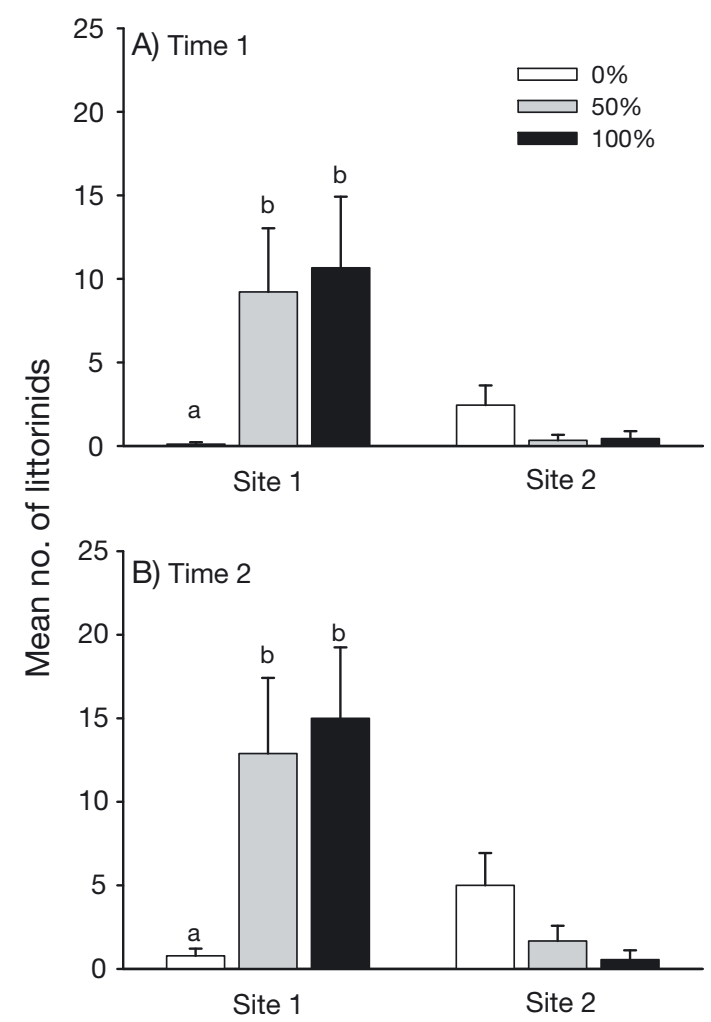

Fig. 3. Mean number (+1 SE) of littorinids (Melaraphe neritoides and Echinolittorina punctata) at southern sites at Time 1 and Time 2 under 100, 50 or 0\% (complete removal) of mean cover of barnacles at each site $(n=9)$. Different letters indicate significantly different treatments (StudentNewman-Keuls test)

ern sites, Time 1: $F_{0_{\mathrm{ROCK}}}=250.72 \pm 24.92, F_{0_{\mathrm{BARN}}}=$ $901.12 \pm 74.79$; Time 2: $F_{0_{\mathrm{ROCK}}}=116.07 \pm 15.16$, $\left.F_{0_{\text {BARN }}}=689.73 \pm 43.34\right)$. This effect was likely due to the 3-dimensional structure and complex microtopography of barnacle assemblages (Thompson et al. 1996). In addition, our data suggested that barnacles were likely able to ameliorate abiotic conditions also for MPB colonizing adjacent rock surfaces and that this effect was density dependent. In particular, MPB biomass values per unit area $\left(F_{0_{\mathrm{ROCK}}}\right)$ were significantly larger at the highest barnacle density $(100 \%)$ than at lower densities (50 and $0 \%$ ) at northern sites (Table S4 in the Supplement). In contrast, the lack of significant effects of barnacle cover on density of limpets indicated that indirect positive effects of high barnacle cover on MPB biomass were negligible in this case (Table S2).

Notwithstanding the facilitative effect on MPB biomass production, barnacle presence did not influence maximum photosynthetic efficiency of microscopic primary producers. This likely reflected a lack 
of change in the identity of biofilm assemblages. Although data on biofilm composition were not available, it is reasonable to suppose that assemblages remained dominated by cyanobacteria, characterized by lower photosynthetic efficiency, but more resistant to desiccation than diatoms (Norton et al. 1990).

In contrast to our prediction, no effects of barnacle cover emerged on total MPB biomass (or maximum photosynthetic efficiency) at the lower latitude in spite of the higher thermal and desiccation stress characterizing southern sites in comparison to northern ones. Geographic variation in barnacle cover might have played a role in driving changes in the intensity of positive interactions (Irving \& Bertness 2009, Maggi et al. 2009). However, although mean barnacle cover was smaller in the South than in the North (see Table S1), significant differences among treatment levels at northern sites suggested that this was not the cause of the lack of effects at southern ones. At northern latitudes, in fact, barnacles exerted significant positive effects on MPB biomass also at absolute percentage covers of $\sim 30 \%$ (i.e. at $50 \%$ of the mean values observed at SN1), which were smaller than $100 \%$ of the mean values observed in the South (which corresponded to absolute values of $\sim 4 \%$ ). In addition, in spite of the declining cover of barnacles at lower latitude, only at southern sites were littorinids positively associated with high barnacle covers. Littorinids are highly mobile herbivores, feeding mostly on MPB (Norton et al. 1990). They can overcome relatively mild stressful conditions through physiological or behavioral adaptation (Garrity 1984, Somero 2002). At southern, warmer sites, however, they may have actively sought a refuge from desiccation by moving to areas shaded by barnacles (Cartwright \& Williams 2012). As littorinids can graze over and between barnacle shells (Creese 1982, Díaz et al. 2012), barnacles might have caused a negative indirect effect on MPB biomass, possibly counterbalancing the positive direct one. Also, slight underestimation of $F_{0}$ sampled over shells in comparison to that sampled on rock surfaces could have marginally contributed to the lack of positive effects of barnacle cover on MPB biomass.

Unexpectedly, analyses did not show any effect of limpets on MPB biomass. At northern sites, the density of limpets was possibly too small to significantly decrease MPB biomass through their grazing activity (Table S1). In contrast, limpets attained relatively large densities in the South, but they were generally smaller than those occurring at northern sites. Due to their small size, some limpets were able to enter the exclusion fences (Table S1), possibly reducing the effect of the Herbivore treatment.

It is important to note that although herbivore effects were traditionally assumed to be negative (Lubchenco \& Gaines 1981), some recent studies confirmed that grazers may also exert facilitative effects on their prey, for example by removing a biofilm-detritus complex and facilitating light and nutrient penetration (Underwood \& Murphy 2008, Skov et al. 2010). In addition, excretion of limiting resources may fertilize MPB assemblages (Plagányi \& Branch 2000).

No direct negative effects of barnacle abundance on densities of limpets were detected at either latitude (Table S2). While at northern sites this could be due to small densities of limpets, at southern sites, the small average size of these grazers might have allowed them to escape the negative influence exerted by barnacles (Creese 1982).

\section{Climatic conditions, density dependence, local stressors and net effect of direct and indirect species interactions}

Natural communities are structured by a complex combination of positive and negative interactions, and the relative importance of each interaction can be a function of both physical and biological conditions (Bruno \& Bertness 2001). By creating habitats and modifying the environment, foundation species exert positive effects on a wide range of organisms (Bruno \& Bertness 2001, Altieri \& van de Koppel 2014 and references therein), thus setting the stage for an ecological network of interactions (Kéfi et al. 2012). Relatively recent studies demonstrated that traits of the benefactor species, such as its density, can modify the strength of facilitation in aquatic systems (Irving \& Bertness 2009, Maggi et al. 2009). Our results showed that barnacles can facilitate MPB and littorinids through density-dependent positive effects resulting from the provision of suitable habitat and likely by ameliorating abiotic conditions on adjacent rock surfaces.

Facilitative effects of foundation species are usually prevalent under more stressful environmental conditions, such as at lower latitudes, where solar stress is greater (Leonard 2000, Bertness \& Ewanchuk 2002). However, effects of large-scale factors, such as those varying with latitude, can be modified by local environmental heterogeneity (Sanford 2014). We argue that local anthropogenic stressors, such as strong nutrient inputs, can also modify the connec- 
tions within an interaction web by influencing the abundance of primary producers. The Mediterranean Sea is an oligotrophic basin characterized by a pattern of decreasing nutrient concentration at decreasing latitude (Garcia et al. 2010). However, local sources of anthropogenic disturbance (e.g. nutrient inputs) likely enriched shallow coastal waters at southern sites. Data on nutrients, oxygen and chl a concentration, collected by the regional agency for environmental protection (ARPA; www.arpa.sicilia.it) during spring-summer 2008, showed that the study area was unexpectedly characterized by eutrophic coastal waters due to anthropogenic sources of organic pollution. This likely resulted in a bottom-up effect on benthic primary producers at southern sites. This positive effect, in addition to the negative effect of littorinids, might have masked a positive effect of high barnacle cover. Larger values attained by MPB biomass at southern sites than at northern sites (1 order of magnitude larger at both times of sampling, Fig. 1) as well as the presence of erect macroalgae only at low latitude (where they attained relatively large abundances) seem to further support the hypothesis of a bottom-up effect. The resulting latitudinal differences in MPB biomass are in sharp contrast with latitudinal patterns observed both in Europe and in Australia, showing a general decline or no variation of MPB standing stock, respectively, with decreasing latitude (Jenkins et al. 2001, Jackson et al. 2010).

Our results suggest the presence of a densitydependent direct facilitative effect of barnacles on biomass of MPB inhabiting Mediterranean rocky shores. Facilitation was likely exerted by providing a refuge to thermal and desiccation stress (Kawai \& Tokeshi 2004), both by adding favourable secondary habitat and by ameliorating abiotic conditions of adjacent primary substratum. This effect was present at northern sites, where physical conditions are relatively mild during colder seasons but where periods of high barometric pressure can lead to a prolonged desiccation stress for MPB biomass (Benedetti-Cecchi et al. 2006). At southern, warmer sites, direct facilitative effects of high cover of barnacles on littorinids as well as a local nutrient input due to anthropogenic activities likely masked the positive effects of increasing barnacle abundance.

Today, a wide range of marine habitats are threatened by a variety of local anthropogenic stressors which undermine the biodiversity and functioning of marine ecosystems (Halpern et al. 2008). Coastal habitats in particular, due to a long history of anthropogenic use, are among those most affected by a wide variety of land- and sea-based drivers (e.g. nutrient input, organic pollution, urban runoff). These local stressors will interact with each other and/or with large-scale climate changes (such as increased global temperature). The combination of these stressors will impact marine ecosystems in a synergistic or at least an additive way (Crain et al. 2008). Previous studies have shown how some species could rely on the presence of foundation species for setting their distributional limits under changing climate conditions (i.e. global warming; Leonard 2000). Results from our study warn that the positive effect of these species might be undermined by the concomitant action of global climate changes and local anthropogenic stressors able to disrupt the complex combinations of species interactions supported by foundations species themselves (Altieri \& van de Koppel 2014).

Acknowledgements. We are grateful to Dr. V. Gennusa, Dr. L. Tamburello and F. Quattrocchi for assistance in the field and to Dr. L. Tamburello and M. Dal Bello for useful discussions and comments on the manuscript.

\section{LITERATURE CITED}

Altieri AH, van de Koppel J (2014) Foundation species in marine ecosystems. In: Bertness MD, Bruno JF, Silliman BR, Stachowicz JJ (eds) Marine community ecology and conservation. Sinauer Associate, Sunderland, MA, p 37-56

$>$ Benedetti-Cecchi L (2000) Predicting direct and indirect interactions during succession in a midlittoral rocky shore assemblage. Ecol Monogr 70:45-72

Benedetti-Cecchi L, Trussell GC (2014) Intertidal rocky shores. In: Bertness MD, Bruno JF, Silliman BR, Stachowicz JJ (eds) Marine community ecology and conservation. Sinauer Associate, Sunderland, MA, p 203-225

Benedetti-Cecchi L, Bertocci I, Vaselli S, Maggi E (2006) Temporal variance reverses the impact of high mean intensity of stress in climate change experiments. Ecology 87:2489-2499

Bertness MD, Callaway R (1994) The role of positive forces in natural communities: a post-cold war perspective. Trends Ecol Evol 9:191-193

Bertness MD, Ewanchuk P (2002) Latitudinal and climatedriven variation in the strength and nature of biological interactions. Oecologia 132:392-401

Bruno J, Bertness MD (2001) Positive interactions, facilitations and foundation species. In: Bertness MD, Gaines SD, Hay M (eds) Marine community ecology. Sinauer Associates, Sunderland, MA, p 201-220

Bulleri F (2009) Facilitation research in marine systems: state of the art, emerging patterns and insights for future developments. J Ecol 97:1121-1130

Cartwright SR, Williams GA (2012) Seasonal variation in utilization of biogenic microhabitats by littorinid snails on tropical rocky shores. Mar Biol 159:2323-2332

Chamberlain SA, Bronstein JL, Rudgers JA (2014) How con- 
text dependent are species interactions? Ecol Lett 17: 881-890

- Crain CM, Kroeker K, Halpern BJ (2008) Interactive and cumulative effects of multiple human stressors in marine systems. Ecol Lett 11:1304-1315

Creese RG (1982) Distribution and abundance of the acmeid limpet, Patelloida latistrigata, and its interaction with barnacles. Oecologia 52:85-96

Crowe TP, Cusson M, Bulleri F, Davoult D and others (2013) Large-scale variation in combined impacts of canopy loss and disturbance on community structure and ecosystem functioning. PLoS ONE 8:e66238

Dayton PK (1972) Toward an understanding of community resilience and the potential effects of enrichments to the benthos at McMurdo Sound, Antarctica. In: Parker BC (ed) Proceedings of the colloquium on conservation problems in Antartica. Allen Press, Lawrence, KS, p 81-96

Della Santina P, Chelazzi G (1991) Temporal organization of foraging in two Mediterranean limpets, Patella rustica and Patella coerulea. J Exp Mar Biol Ecol 153:75-85

> Dethier MN, Graham ES, Cohen S, Tear LM (1993) Visual versus random-point percent cover estimations: 'objective' is not always better. Mar Ecol Prog Ser 96:93-100

> Díaz ER, Kraufvelin P, Erlandsson J (2012) Combining gut fluorescence technique and spatial analysis to determine Littorina littorea grazing dynamics in nutrient-enriched and nutrient-unenriched littoral mesocosms. Mar Biol 159:837-852

> Doxford SW, Ooi MKJ, Freckleton RP (2013) Spatial and temporal variability in positive and negative plantbryophyte interactions along a latitudinal gradient. J Ecol 101:465-474

Dungan ML (1986) Three-way interactions: barnacles, limpets, and algae in a Sonoran desert rocky intertidal zone. Am Nat 127:292-316

Fischer AG (1960) Latitudinal variations in organic diversity. Evolution 14:64-81

Freidenburg TL, Menge BA, Halpin PM, Webster M, SuttonGrier A (2007) Cross-scale variation in top-down and bottom-up control of algal abundance. J Exp Mar Biol Ecol 347:8-29

Garrity SD (1984) Some adaptations of gastropods to physical stress on a tropical rocky shore. Ecology 65:559-574

> Halpern BS, Walbridge S, Selkoe KA, Kappel CV and others (2008) A global map of human impact on marine ecosystems. Science 319:948-952

Hawkins SJ, Hartnoll RG (1983) Grazing of intertidal algae by marine invertebrates. Oceanogr Mar Biol Annu Rev 21:195-282

> Holt RD (1977) Predation, apparent competition, and the structure of prey communities. Theor Popul Biol 12: 197-229

Irving AD, Bertness MD (2009) Trait-dependent modification of facilitation on cobble beaches. Ecology 90: 3042-3050

> Jackson AC, Underwood AJ, Murphy RJ, Skilleter GA (2010) Latitudinal and environmental patterns in abundance and composition of epilithic microphytobenthos. Mar Ecol Prog Ser 417:27-38

> Jenkins SR, Arenas F, Arrontes J, Bussell J and others (2001) European-scale analysis of seasonal variability in limpet grazing activity and microalgal abundance. Mar Ecol Prog Ser 211:193-203

Kawai T, Tokeshi M (2004) Variable modes of facilitation in the upper intertidal: goose barnacles and mussels. Mar Ecol Prog Ser 272:203-213

Kéfi S, Berlow EL, Wieters E, Navarrete SA and others (2012) More than a meal... integrating non-feeding interactions into food webs. Ecol Lett 15:291-300

Leonard GH (2000) Latitudinal variation in species interactions: a test in the New England rocky intertidal zone. Ecology 81:1015-1030

Leonard LA, Luther ME (1995) Flow hydrodynamics in tidal marsh canopies. Limnol Oceanogr 40:1474-1484

Lubchenco J, Gaines SD (1981) A unified approach to marine plant-herbivore interactions. I. Populations and community. Annu Rev Ecol Syst 12:405-437

Maggi E, Bertocci I, Vaselli S, Benedetti-Cecchi L (2009) Effects of changes in number, identity and abundance of habitat-forming species on assemblages of rocky seashores. Mar Ecol Prog Ser 381:39-49

> Maggi E, Jackson AC, Tolhurst T, Underwood AJ, Chapman MG (2013) Changes in microphytobenthos fluorescence over a tidal cycle: implications for sampling designs. Hydrobiologia 701:301-312

- Menge BA (1995) Indirect effects in marine intertidal interaction webs: patterns and importance. Ecol Monogr 65:21-74

Menge BA, Branch GM (2001). Rocky intertidal communities. In: Bertness MD, Gaines SD, Hay ME (eds) Marine community ecology. Sinauer Associates, Sunderland, MA, p 221-251

Menge BA, Olson AM (1990) Role of scale and environmental factors in regulation of community structure. Trends Ecol Evol 5:52-57

Menge BA, Sanford E, Daley BA, Freidenburg TL, Hudson G, Lubchenco J (2002) An interhemispheric comparison of bottom-up effects on community structure: insights revealed using the comparative-experimental approach. Ecol Res 17:1-16

Menge BA, Bracken M, Foley M, Freidenburg T and others (2003) Coastal oceanography sets the pace of rocky intertidal community dynamics. Proc Natl Acad Sci USA 100: 12229-12234

Garcia HE, Locarnini RA, Boyer TP, Antonov JI, Zweng MM, Baranova OK, Johnson DR (2010) World ocean atlas 2009, volume 4: nutrients (phosphate, nitrate, and silicate). In: Levitus S (ed) NOAA Atlas NESDIS 71. US Government Printing Office, Washington, DC

Norton TA, Hawkins SJ, Manley NL, Williams GA, Watson DC (1990) Scraping a living: a review of littorinid grazing. Hydrobiologia 193:117-138

Paine RT (1980) Food webs: linkage, interaction strength and community infrastructure. J Anim Ecol 49:666-685

Pennings S, Silliman BR (2005) Linking biogeography and community ecology: latitudinal variation in plant-herbivore interaction strength. Ecology 86:2310-2319

Plagányi ÉE, Branch GM (2000) Does the limpet Patella cochlear fertilize its own algal garden? Mar Ecol Prog Ser 194:113-122

R Development Core Team (2013) R: a language and environment for statistical computing, version 2.15.3. R Foundation for Statistical Computing, Vienna. www.r-project.org

Sanford E (2014) The biogeography of marine communities. In: Bertness MD, Bruno JF, Silliman BR, Stachowicz JJ (eds) Marine community ecology and conservation. Sinauer Associate, Sunderland, MA, p 131-163

Serodio J, Marques da Silva J, Catarino F (1997) Nonde- 
structive tracing of migratory rhythms of intertidal benthic microalgae using in vivo chlorophyll a fluorescence. J Phycol 33:542-553

Skov MW, Volkelt-Igoe M, Hawkins SJ, Jesus B, Thompson RC, Doncaster CP (2010) Past and present grazing boosts the photo-autotrophic biomass of biofilms. Mar Ecol Prog Ser 401:101-111

Somero GN (2002) Thermal physiology and vertical zonation of intertidal animals: optima, limits and costs of living. Integr Comp Biol 42:780-789

Stephenson TA, Stephenson A (1949) The universal features of zonation between the tidemarks on rocky coasts. J Ecol 37:289-305

Thompson JN, Cunningham BM (2002) Geographic structure and dynamics of coevolutionary selection. Nature 417:735-738

Thompson RC, Wilson BJ, Tobin ML, Hill AS, Hawkins SJ (1996) Biologically generated habitat provision and diversity of rocky shore organisms at a hierarchy of spatial scales. J Exp Mar Biol Ecol 202:73-84

Editorial responsibility: Antony Underwood, Sydney, NSW, Australia
Thompson RC, Roberts MF, Norton TA, Hawkins SJ (2000) Feast or famine for intertidal grazing molluscs: a mismatch between seasonal variations in grazing intensity and the abundance of microbial resources. Hydrobiologia 440:357-367

Thompson RC, Norton TA, Hawkins SJ (2004) Physical stress and biological regulation control pattern and process in benthic biofilms. Ecology 85:1372-1382

Underwood AJ (1979) The ecology of intertidal gastropods. Adv Mar Biol 16:111-210

Underwood AJ, Murphy RJ (2008) Unexpected patterns of facilitatory grazing revealed by quantitative imaging. Mar Ecol Prog Ser 358:85-94

Williams GA, Davies MS, Nagarkar S (2000) Primary succession on a seasonal tropical rocky shore: the relative roles of spatial heterogeneity and herbivory. Mar Ecol Prog Ser 203:81-94

Wootton JT (1993) Indirect effects and habitat use in an intertidal community: interaction chains and interaction modifications. Am Nat 141:71-89

Submitted:February 19, 2015; Accepted: July 8, 2015

Proofs received from author(s): August 19, 2015 